\title{
ПИЩЕВАЯ ЦЕННОСТЬ ПОРОШКА ИЗ ТОМАТОВ, ВЫРАЩЕННЫХ В РАЗНЫХ ГЕОГРАФИЧЕСКИХ РАЙОНАХ ЧЕЛЯБИНСКОЙ ОБЛАСТИ
}

\author{
${ }^{1}$ Н.Л. Наумова, доктор технических наук, профессор \\ ${ }^{2}$ В.В. Журавель, кандидат сельскохозяйственных наук \\ ${ }^{2}$ Е.А. Бурмистров, кандидат сельскохозяйственных наук \\ ${ }^{2}$ О.М. Бурмистрова, кандидат сельскохозяйственных наук, доцент \\ ${ }^{1}$ Южно-Уральский государственный университет (НИУ) \\ ${ }^{2}$ Южно-Уральский государственный аграрный университет \\ E-mail:n.naumova@inbox.ru
}

Ключевые слова: томатный порошок, пищевая ценность сырья, качество, безопасность.

Реферат. Решение проблемы комплексной переработки томатного сырья с получением конкурентоспособных продуктов отягощено рядом экологических проблем, в первую очередь антропогенной нагрузкой на почвы агроценозов. На территории Челябинской области имеются как естественные, так и искусственные геохимические провиниии, в условиях которых осуществляется интенсивное сельскохозяйственное производство. Целью исследований стало изучение пищевой ценности порошка из томатов, выращенных в разных географических районах Челябинской области. Объектами изучения послужили пробы томатного порошка, полученного при сушке помидоров сорта Огни Москвы, выращенных в открытом грунте в разных садовых некоммерческих товариществах: проба № 1 - в СНT «Локомотив-1» (2. Челябинск, Троицкий тракт), проба № 2 - в СНТ «Дизелист-1» (Челябинская обл., 2. Троиик, ул. Дизельная). Установлено, что в пробе № 1 содержится больше олова (в 4,1 раза), лития (в 3,3 раза), свинца (в 2 раза, но не выше нормы), кобальта (в 1,6 раза), хрома (на 18,5\%), калия (на 8,7\%), а также серебра, теллура, титана, ванадия и незаменимого нутриента - белка (на 5,6\%). Обнаруженные количества олова и серебра превышают кларковые значения, характерные для сухой фитомассы растительности суши, в 2,5 и 2 раза соответственно. В пробе № 2 содержстся больше липидов (в 1,7 раза) и сахаров (на 14,1\%), пищевых волокон (на 14,6 \%) и органических кислот (на 1,3-4,7\%), минеральных элементов: кремния и алюминия (в 14-14,6 раза), селена (в 4 раза), бора (в 3,6 раза), кальция (в 2,7 раза), марганциа (в 2,6 раза), цинка (в 2,1 раза), меди (в 2 раза), магния и стронция (в 1,8 раза). Уровень селена превышает кларковые значения в 21 раз. Таким образом, сельскохозяйственная продукция, получаемая в агроченозах, неблагополучных по содержанию поллютантов, нуждается в особо строгом контроле последних как в почвенном, так и в сырьевом материале.

Одним из важнейших преимуществ сушки растительного сырья является возможность производства продуктов без консервантов, наполнителей, ароматизаторов и других пищевых добавок. Сушеные томаты можно применять в домашней кулинарии и на предприятиях общественного питания при приготовлении широкого ассортимента обеденных блюд, сухих приправ, соусов, соков, сухих супов и чипсов $[1,2]$. Томатный порошок имеет высокую биологическую ценность, антиоксидантную активность и проявляет иммунозащитные свойства. В сушёных томатах в высококонцентрированном виде находятся различные БАВ: ликопин, $\beta$-каротин, витамины E, $\mathrm{B}_{1}, \mathrm{~B}_{2}, \mathrm{~B}_{6}, \mathrm{~B}_{9}, \mathrm{H}, \mathrm{PP}$, минеральные (калий, натрий, фосфор, магний, железо, цинк, медь) и пектиновые вещества, пищевые волокна, полифенолы и флавоноиды [3-6]. Высокое содержание в мякоти и кожице томатов ликопина позволяет обогащать им другие пищевые продукты [7]. Преимущества овощных добавок, балансирующих недостатки витаминов, минеральных веществ, пищевых волокон, заключаются в их доступности, низкой себестоимости за счет безотходной переработки исходного сырья [8].

Решение проблемы комплексной переработки томатного сырья с получением конкурентоспособных продуктов отягощено рядом экологических проблем, в первую очередь антро- 
погенной нагрузкой на почвы агроценозов $[4,5]$. На территории Челябинской области имеются как естественные, так и искусственные геохимические провинции, в условиях которых осуществляется интенсивное сельскохозяйственное производство. Так, на территории Чебаркульского района фиксируются высокие концентрации марганца в почве. В северной части Красноармейского района установлены локальные аномалии меди - до 200, цинка - до 700, свинца - до 70, хрома и стронция - до 300 мг/кг [9]. В этой связи целью исследований стало изучение пищевой ценности порошка из томатов, выращенных в разных географических районах Челябинской области.

Объектами изучения послужили пробы томатного порошка, полученного при сушке помидоров сорта Огни Москвы, выращенных в открытом грунте: проба № 1 - в садовом некоммерческом товариществе (СНТ) «Локомотив-1» (г. Челябинск, Троицкий тракт), проба № 2 в СНТ «Дизелист-1» (Челябинская обл., г. Троицк, ул. Дизельная).

Для получения томатного порошка помидоры нарезали кружочками толщиной 2 мм и высушивали в дегидраторе Kitfort-1905 при температуре $70{ }^{\circ} \mathrm{C}$ в течение 48 ч. Степень готовности (сушки) определяли по ломкости продукта. Высушенные пробы томатов измельчали на бытовой кофемолке. По внешнему виду исследуемые пробы томатного порошка не имели никаких различий. По консистенции полученный продукт представлял собой порошкообразную массу тонкого измельчения, оранжево-красного цвета, приятного кисловато-сладкого вкуса, свойственного запаха.

Массовую долю влаги в сырье определяли по ГОСТ 9404-88, белка - по ГОСТ 10846-91, жира - по МУ 4237-86, сахаров - по ГОСТ 8756.13-87, содержание органических кислот - по М 04-47-12, каротиноидов - по ГОСТ Р 54058-10, минеральных веществ - по МУК 4.1.1482-03 и МУК 4.1.1483-03, пищевых волокон - классическим методом [10].

Все исследования проводились в трехкратной повторности. Результаты представлены в виде среднего значения и стандартного отклонения. Статистический анализ проводился с использованием пакета программ Microsoft Excel XP и Statistica 8.0. Статистическая погрешность данных не превышала 5 \% (при уровне достоверности 95 \%).

В ходе испытаний было выявлено, что исследуемые пробы томатного порошка не имеют различий по влажности и количеству каротиноидов (табл. 1). Установленный уровень (412,0415,0 мг/кг) содержания каротиноидов, обладающих высокой антиоксидантной активностью, позволяет рассматривать его в качестве средства для снижения риска развития рака и ишемической болезни сердца. Для сравнения, содержание каротиноидов в облепихе сублимационной сушки составляет $550,1 \pm 19,3$ мг/кг.

При этом по количеству основных нутриентов определены некоторые колебания. Так, в пробе №2 содержится больше липидов (в 1,7 раза), сахаров (на 14,1 \%), пищевых волокон (на 14,6 \%), в пробе №1 - больше белка (на 5,6 \%).

Установлено, что из органических кислот в обеих пробах томатного порошка преобладают лимонная (3740,0-3887,0 мг/кг), винная (954,6-966,9 мг/кг), уксусная $(873,4-891,9$ мг/кг), присутствует также янтарная (282,2-295,4 мг/кг). На уровне следов (<1,0 мг/кг) обнаружены щавелевая, яблочная, молочная, муравьиная кислоты. При этом в пробе №2 выявленных кислот содержится несколько больше (на 1,3-4,7 \%).

Сравнение полученных результатов с общеизвестными данными о химическом составе томатного порошка, показывает, что исследуемые образцы несколько отличаются от литературных данных по количеству белка (на 18,7-23,0 \%), жира (в 1,6-3,4 раза), сахаров (на 11,522,4 \%) и пищевых волокон (в 2,2-2,6 раза) в меньшую сторону. Это может быть обусловлено как относительно высокой (в 1,6-3,7 раза) влажностью изучаемых проб сырья, так и ботаническими особенностями сорта помидоров. 
Физико-химические показатели и пищевая ценность томатного порошка

\begin{tabular}{|l|c|c|c|}
\hline \multicolumn{1}{|c|}{ Показатель } & Литературные данные & \multicolumn{2}{c|}{ Полученные результаты } \\
\cline { 3 - 4 } & {$[7,11]$} & проба №1 & проба №2 \\
\hline Содержание жира, г/100 г & 3,1 & $1,1 \pm 0,1$ & $1,9 \pm 0,2$ \\
\hline Содержание белка, г/100 г & 13,9 & $11,3 \pm 0,4$ & $10,7 \pm 0,3$ \\
\hline Массовая доля влаги, \% & $3-7$ & $11,1 \pm 0,2$ & $11,0 \pm 0,2$ \\
\hline Массовая доля сахаров, \% & 34,8 г/100 г & $27,0 \pm 1,5$ & $30,8 \pm 1,6$ \\
\hline Содержание каротиноидов, мг/кг & - & $415,0 \pm 17,3$ & $412,0 \pm 19,2$ \\
\hline Содержание органических кислот, мг/кг, из них & - & & $<1,0$ \\
\hline щавелевой & & $954,6 \pm 21,2$ & $966,9 \pm 23,4$ \\
\hline винной & & $<1,0$ & $<1,0$ \\
\hline яблочной & & $3740,0 \pm 63,5$ & $3887,0 \pm 71,2$ \\
\hline лимонной & & $282,2 \pm 9,4$ & $295,4 \pm 10,6$ \\
\hline янтарной & & $873,4 \pm 17,8$ & $891,9 \pm 19,4$ \\
\hline уксусной & & $<1,0$ & $<1,0$ \\
\hline молочной & & $4,8 \pm 0,4$ & $<1,0$ \\
\hline муравьиной & & & $5,5 \pm 0,3$ \\
\hline Содержание пищевых волокон, г/100 г & 12,4 & & $<1,0$ \\
\hline
\end{tabular}

На фоне того, что коллективные сады играют большую роль в жизни крупных городов в части обеспечения населения продовольствием, почвы многих из них считаются крайне неблагополучными из-за загрязнения рядом тяжелых металлов. Так, почвы СНТ восточной части г. Челябинска характеризуются превышением ориентировочно допустимых концентраций по никелю (до 4,4 раза), цинку (до 3 раз), свинцу (до 30 \%), северной части - по цинку (до 2 раз), меди (до $36 \%$ ), кадмию (до $10 \%$ ), западной части - по цинку (до 2,3 раза) [12]. Тяжелые металлы в таких количествах являются сильными стресс-факторами и мощными токсикантами, с которыми сталкиваются растения в связи с нарастающим антропогенным воздействием на окружающую среду [13]. Многими учеными подтверждена миграция химических элементов по пищевым цепочкам, неблагоприятный химический состав любого звена которых может привести к пагубным изменениям в организме человека [14-16]. В этой связи был изучен минеральный состав полученного томатного порошка (табл. 2).

Выявлено, что минеральные вещества представлены 25 наименованиями, что свидетельствует о богатом элементном составе исследуемого сырья. Установлено, что в пробе № 1 содержится больше олова (в 4,1 раза), лития (в 3,3 раза), свинца (в 2 раза, но не выше нормы), кобальта (в 1,6 раза), хрома (на 18,5 \%), калия (на 8,7 \%), а также серебра, теллура, титана и ванадия, т.е. элементов, свидетельствующих о техногенной нагрузке на почву, используемую для выращивания томатов. Для пробы № 2, напротив, характерно повышенное количество макро- и микроэлементов, необходимых для полноценной жизнедеятельности человека, а именно кремния (в 14,6 раза), селена (в 4 раза), кальция (в 2,7 раза), марганца (в 2,6 раза), цинка (в 2,1 раза), меди (в 2 раза), магния (в 1,8 раза), фосфора (на 46,1 \%). Наряду с этим в пробе № 2 также выявлено относительно высокое количество стронция (в 1,8 раза), алюминия (в 14 раз), бора (в 3,6 раза), что опосредованно характеризует специфику биогеохимических свойств применяемого для культивирования грунта.

В сравнительном аспекте с результатами, полученными рядом ученых при изучении элементного состава аналогичного сырья, определено, что исследуемый материал несколько уступает по содержанию меди (в 2,3-4,7 раза), железа (в 3,8-4 раза), натрия (в 2,4-2,8 раза) и др. Кларковые значения минеральных элементов, установленные для сухой фитомассы раститель- 
ности суши, наглядно свидетельствуют о превышении в пробе № 1 уровней селена (в 5,2 раза), олова (в 2,5 раза) и серебра (в 2 раза), в пробе № 2 - селена (в 21 раз).

Необходимо помнить, что селен - это не только эссенциальный ультрамикроэлемент, но и токсикант первого класса опасности. В условиях хронического потребления высоких доз селена происходит поражение печени, почек, кожи, суставов, потеря аппетита, расстройства пищеварения, выраженный дерматит, болезненные изменения ногтей и подкожный отек, головокружения, крайняя утомляемость, выкидыши, врожденные уродства [20]. В этой связи особую актуальность приобретает сельскохозяйственное районирование с учетом биогеохимических особенностей региона.

В обеих пробах томатного порошка не было зафиксировано наличия таких тяжелых металлов, как мышьяк, кадмий и ртуть.

Таблииа 2

Минеральный состав томатного порошка, мг/кг

\begin{tabular}{|c|c|c|c|}
\hline \multirow[t]{2}{*}{ Минеральный элемент } & \multirow{2}{*}{\begin{tabular}{|c|} 
Литературные данные \\
{$[11,17,18]$}
\end{tabular}} & \multicolumn{2}{|c|}{ Полученные результаты } \\
\hline & & проба №1 & проба №2 \\
\hline $\mathrm{Ag}$ & $0,03 * *$ & $0,060 \pm 0,002$ & - \\
\hline $\mathrm{Al}$ & - & $2,73 \pm 0,04$ & $38,41 \pm 1,40$ \\
\hline B & $25^{* *}$ & $5,28 \pm 0,16$ & $18,90 \pm 0,91$ \\
\hline $\mathrm{Ca}$ & $1090-1120$ & $770,10 \pm 20,14$ & $2070,78 \pm 93,04$ \\
\hline Co & $0,5^{* *}$ & $0,021 \pm 0,002$ & $0,013 \pm 0,02$ \\
\hline $\mathrm{Cr}$ & $1,8^{* *}$ & $0,32 \pm 0,04$ & $0,27 \pm 0,02$ \\
\hline $\mathrm{Cu}$ & $14,0-14,3$ & $2,98 \pm 0,34$ & $5,95 \pm 0,47$ \\
\hline $\mathrm{Fe}$ & $90,8-91,0$ & $22,32 \pm 1,26$ & $23,92 \pm 1,09$ \\
\hline $\mathrm{K}$ & $34260-34300$ & $61697,11 \pm 244,45$ & $56352,54 \pm 195,23$ \\
\hline $\mathrm{Li}$ & $1,5^{* *}$ & $0,161 \pm 0,007$ & $0,048 \pm 0,003$ \\
\hline $\mathrm{Mg}$ & $1930-1950$ & $696,20 \pm 19,32$ & $1281,42 \pm 37,22$ \\
\hline $\mathrm{Mn}$ & $205^{* *}$ & $5,37 \pm 0,26$ & $14,08 \pm 0,71$ \\
\hline Mo & - & $0,85 \pm 0,02$ & $1,21 \pm 0,06$ \\
\hline $\mathrm{Na}$ & 1160 & $414,14 \pm 17,28$ & $474,73 \pm 15,07$ \\
\hline $\mathrm{Ni}$ & $2 * *$ & $0,18 \pm 0,03$ & $0,25 \pm 0,04$ \\
\hline $\mathrm{P}$ & $3550-3570$ & $3218,23 \pm 110,56$ & $4703,92 \pm 124,73$ \\
\hline $\mathrm{Pb}$ & Не более $0,5^{*}$ & $0,10 \pm 0,02$ & $0,05 \pm 0,01$ \\
\hline $\mathrm{Se}$ & $0,05 * *$ & $0,26 \pm 0,04$ & $1,05 \pm 0,06$ \\
\hline $\mathrm{Si}$ & - & $8,01 \pm 0,26$ & $117,30 \pm 3,68$ \\
\hline $\mathrm{Sn}$ & $0,25 * *$ & $0,62 \pm 0,02$ & $0,15 \pm 0,01$ \\
\hline $\mathrm{Sr}$ & $35 * *$ & $4,82 \pm 0,11$ & $8,50 \pm 0,43$ \\
\hline $\mathrm{Te}$ & - & $0,09 \pm 0,01$ & - \\
\hline $\mathrm{Ti}$ & $32,5 * *$ & $0,10 \pm 0,02$ & - \\
\hline $\mathrm{W}$ & - & $0,08 \pm 0,01$ & - \\
\hline $\mathrm{Zn}$ & $19-22$ & $11,71 \pm 0,62$ & $24,95 \pm 0,93$ \\
\hline
\end{tabular}

*Норма согласно СанПиН 2.3.2.1078-01; **кларковые значения (в сухой фитомассе) [19].

Проведенные исследования позволяют сделать следующие выводы:

1. Томатный порошок, полученный из одного сорта помидоров, выращенных в разных географических районах Челябинской области, не имеет существенных различий по органолептическим показателям. 
2. В сырье, полученном при сушке томатов из СНТ «Локомотив-1», содержится больше олова (в 4,1 раза), лития (в 3,3 раза), свинца (в 2 раза, но не выше нормы), кобальта (в 1,6 раза), хрома (на 18,5 \%), калия (на 8,7 \%), а также серебра, теллура, титана, ванадия и незаменимого нутриента - белка (на 5,6 \%). При этом обнаруженные количества олова и серебра превышают кларковые значения, характерные для сухой фитомассы растительности суши в 2,5 и 2 раза соответственно.

3. Сухой растительный материал из томатов, выращенных в СНТ «Дизелист-1», содержит больше не только питательных веществ - липидов (в 1,7 раза) и сахаров (на 14,1 \%), а также пищевых волокон (на 14,6 \%) и органических кислот (на 1,3-4,7 \%), но и минеральных элементов: кремния и алюминия (в 14-14,6 раза), селена (в 4 раза), бора (в 3,6 раза), кальция (в 2,7 раза), марганца (в 2,6 раза), цинка (в 2,1 раза), меди (в 2 раза), магния и стронция (в 1,8 раза). По уровню селена этот образец превышает кларковые значения в 21 раз.

4. Сельскохозяйственная продукция, получаемая в агроценозах, неблагополучных по содержанию поллютантов, нуждается в особо строгом контроле последних как в почвенном, так и в сырьевом материале.

\section{БИБЛИОГРАФИЧЕСКИЙ СПИСОК}

1. Гуськова К.Ю. Томатный порошок как функциональная добавка в технологии изделий из бисквитного теста // Инновации и технологии в биомедицине: сб. тр. в науч.-практ. конф. 2020. - С. 39-40.

2. Разработка технологии и рецептуры сдобных булочных изделий, обогащенных пищевыми добавками / М.А. Казимирова, Т.В. Першакова, А.Н. Матвиенко, Т.А. Шахрай, О.В. Федосеева // Новые технологии. - 2018. - № 1. - С. 37-42.

3. Технология получения сухих и вяленых томатов, сухих томатных порошков / А.М. Гаджиева, М.С. Мурадов, Г.И. Касьянов, Е.Г. Кубенко, О.И. Квасенков // Хранение и переработка сельхозсырья. - 2015. - № 8. - С. 21-24.

4. Гаджиева A.M. Технологии комплексной переработки томатов с использованием различных способов сушки // Известия высших учебных заведений. Пищевая технология. - 2015. - № $1(343) .-$ C. $42-45$.

5. Использование томатного порошка в национальных дагестанских хлебобулочных изделиях / А. Гаджиева, Д. Маллаева, 3. Муртазалиева, Д. Мурадова // Повышение качества и безопасности пищевых продуктов: материалы Х Всерос. науч.-практ. конф. - 2020. - С. 18-21.

6. Афонькина B.A., Попов В.М., Левинский В.Н. Результаты исследований качественных показателей процесса ИК-сушки томатов с установкой сроков хранения // Вестник КрасГАУ. 2018. - № 4 (139). - С. 174-180.

7. Остриков А.Н., Гаджиева А.М., Касьянов Г.И. Комплексная технология переработки томатного сырья // Вестник Воронежского государственного университета инженерных технологий. - 2015. - № 1 (63). - С. 12-17.

8. Воронина П.К. Применение сушеных томатов в технологии приготовления кексов // Инновационная техника и технология. - 2016. - № 2 (7). - С. 9-14.

9. Гертман А.М., Самсонова Т.С. Способы коррекции обменных процессов при незаразной патологии продуктивных коров в условиях техногенных провинций Южного Урала // Известия Оренбургского аграрного университета. - 2014. - №1 (45). - С. 65-68.

10. Руководство по методам анализа качества и безопасности пищевых продуктов / И.М. Скурихин, В.А. Тутельян. - М.: Брандес, Медицина, 1998. - 342 с. 
11. Попов B.М., Афонькина В.А., Левинский В.Н. Результаты исследований качественных показателей процесса ИК-сушки томатов по содержанию аскорбиновой кислоты // Международный научно-исследовательский журнал. - 2017. - № 9-3 (63). - С. 58-62.

12. Маркова Л.М. Оценка загрязнения тяжелыми металлами почв садовых агроценозов г. Челябинска // Почвы в биосфере: сб. материалов всерос. науч. конф. с междунар. участием, посвящ. 50-летию Ин-та почвоведения и агрохимии СО РАН. - 2018. - С. 309-313.

13. Изменчивость антиоксидантной активности можжевельника казацкого в градиенте содержания ионов меди на Южном Урале / А.В. Щербаков, С.Р. Рахматуллина, М.В. ЧистяковаМавлетова, И.Ю. Усманов // Вестник Башкирского университета. - 2013. - Т. 18, № 4. - С. 10811084.

14. Актуальность оценки многосредового канцерогенного риска для здоровья населения от воздействия химических веществ, загрязняющих окружающую среду / В.И. Курчанов, Т.Е. Лим, И.А. Воецкий, С.А. Голованин // Здоровье населения и среда обитания. - 2015. - № 7 (268). - C. 8-12.

15. Сусликов В.Л. Геохимическая экология болезней. Т. 2: Атомовиты. - М.: Гелиос АРВ, 2000. $-672 \mathrm{c}$.

16. Ягодин Б.А. Тяжелые металлы и здоровье человека // Химия в сельском хозяйстве. 1995. - № 4. - C. 18-20.

17. Гаджиева А.М., Алиева М.Г. Получение и рациональное использование вторичных ресурсов сырья на основе комплексной переработки томатов // Совершенствование технологических процессов в пищевой промышленности: сб. науч. трудов преподавателей, сотрудников, аспирантов и студентов технологического факультета ДГТУ. - 2016. - С. 37-43.

18. Гаджиева А.М., Алиева М.Г. Особенности технологии производства продуктов с промежуточной влажностью на основе томатного сырья // Неделя науки - 2016: материалы XXXVII итоговой науч.-техн. конф. ДГТУ. - 2016. - С. 132-134.

19. Добровольский В.В. Основы биогеохимии. - М.: Академия, 2003. -400 с.

20. Селен и наноселен: роль в организме та использование в медицинской практике / Н.С. Ноцек, Н.О. Горчакова, И.Ф. Беленичев, А.Н. Пузыренко, И.С. Чекман // Украинский научно-медицинский молодежный журнал. - 2015. - № 4 (91). - С. 129-133.

\section{REFERENCES}

1. Gus'kova K.Yu. Tomatnyj poroshok kak funkcional'naya dobavka v tekhnologii izdelij iz biskvitnogo testa (Tomato powder as a functional additive in the technology of biscuit dough products), Proceedings of the Conference, 2020, pp. 39-40. (In Russ.)

2. Kazimirova M.A., Pershakova T.V., Matvienko A.N., Shahraj T.A., Fedoseeva O.V., Novye tekhnologii, 2018, No. 1, pp. 37-42. (In Russ.)

3. Gadzhieva A.M., Muradov M.S., Kas'yanov G.I., Kubenko E.G., Kvasenkov O.I., Hranenie $i$ pererabotka sel'hozsyr'ya, 2015, No. 8, pp. 21-24. (In Russ.)

4. Gadzhieva A.M., Izvestiya vysshih uchebnyh zavedenij. Pishchevaya tekhnologiya, 2015, No. 1 (343), pp. 42-45. (In Russ.)

5. Gadzhieva A., Mallaeva D., Murtazalieva Z., Muradova D. Ispol'zovanie tomatnogo poroshka v nacional'nyh dagestanskih hlebobulochnyh izdeliyah (The use of tomato powder in national Dagestan bakery products), Proceedings of the 10th All-Russian Scientific and Practical Conference, 2020, pp. 18-21. (In Russ.)

6. Afon'kina V.A., Popov V.M., Levinskij V.N. Vestnik KrasGAU, 2018, No. 4 (139), pp. 174180. (In Russ.) 
7. Ostrikov A.N., Gadzhieva A.M., Kas'yanov G.I. Vestnik Voronezhskogo gosudarstvennogo universiteta inzhenernyh tekhnologij, 2015, No. 1 (63), pp. 12-17. (In Russ.)

8. Voronina P.K. Innovacionnaya tekhnika i tekhnologiya, 2016, No. 2 (7), pp. 9-14. (In Russ.)

9. Gertman A.M., Samsonova T.S. Izvestiya Orenburgskogo agrarnogo universiteta, 2014, No 1 (45), pp. 65-68. (In Russ.)

10. Skurihina I.M., Tutel'yana V.A., Rukovodstvo po metodam analiza kachestva i bezopasnosti pishchevyh produktov (Guidelines on methods for analyzing the quality and safety of food products), Moscow: Brandes, Medicina, 1998, 342 p.

11. Popov V.M., Afon'kina V.A., Levinskij V.N. Mezhdunarodnyj nauchno-issledovatel'skij zhurnal, 2017, No. 9-3 (63), pp. 58-62. (In Russ.)

12. Markova L.M. Ocenka zagryazneniya tyazhelymi metallami pochv sadovyh agrocenozov g. Chelyabinska (Assessment of heavy metal pollution of soils of garden agrocenoses in Chelyabinsk), Proceedings of the All-Russian Scientific Conference with International Participation, 2018, pp. 309313. (In Russ.)

13. Shcherbakov A.V., Rahmatullina S.R., Chistyakova-Mavletova M.V., Usmanov I.Yu. Vestnik Bashkirskogo universiteta, 2013, vol. 18, No. 4, pp. 1081-1084. (In Russ.)

14. Kurchanov V.I., Lim T.E., Voeckij I.A., Golovanin S.A. Zdorov'e naseleniya i sreda obitaniya, 2015, No. 7 (268), pp. 8-12. (In Russ.)

15. Suslikov V.L. Geohimicheskaya ekologiya boleznej (Geochemical ecology of diseases), vol. 2. Atomovites, Moscow: Gelios ARV, 2000, 672 p.

16. Yagodin B.A. Himiya v sel'skom hozyajstve, 1995, No. 4, pp. 18-20. (In Russ.)

17. Gadzhieva A.M., Alieva M.G. Poluchenie i racional'noe ispol'zovanie vtorichnyh resursov syr'ya na osnove kompleksnoj pererabotki tomatov (Obtaining and rational use of secondary raw materials based on complex processing of tomatoes), Proceedings of Scientific Papers, 2016, pp. 37-43. (In Russ.)

18. Gadzhieva A.M., Alieva M.G. Osobennosti tekhnologii proizvodstva produktov s promezhutochnoj vlazhnost'yu na osnove tomatnogo syr'ya (Features of the technology for the production of products with intermediate moisture based on tomato raw materials), Proceedings of the 37th Final Scientific and Technical Conference of DSTU, 2016, pp. 132-134. (In Russ.)

19. Dobrovol'skij V.V. Osnovy biogeohimii (Basics of biogeochemistry), Moscow: Academy, 2003, $400 \mathrm{p}$.

20. Nocek N.S., Gorchakova N.O., Belenichev I.F., Puzyrenko A.N., Chekman I.S., Ukrainskij nauchno-medicinskij molodezhnyj zhurnal, 2015, No. 4 (91), pp. 129-133. 